\title{
HISTOLOGY OF CANCELLOUS IMPACTION
}

\section{GRAFTING IN THE FEMUR}

\author{
A CASE REPORT
}

\author{
R. S. M. LING, A. J. TIMPERLEY, L. LINDER
}

From Princess Elizabeth Orthopaedic Hospital, Exeter, England and Gävle Hospital, Sweden

\begin{abstract}
We report the histology of a femur retrieved 3.5 years after a cemented revision of a hip replacement in which impaction allografting had been used to fill two large cortical defects. The allograft chips had largely been replaced by viable cortical bone, and the interface between cement and tissue resembled that seen after primary cemented arthroplasty.
\end{abstract}

J Bone Joint Surg [Br] 1993; 75-B:693-6.

Received 14 October 1992; Accepted 11 February 1993

Cementing a femoral stem into a concentric layer of impacted cancellous bone chips has proved to be a promising method of dealing with deficient bone stock in the revision of the femoral component of hip arthroplasties (Gie et al 1993). The radiographic and clinical results have been very satisfactory but the underlying biology is unknown. We therefore report the first histological study of a case after cancellous impaction grafting of the femur. The case was not included in our previously published clinical review of impaction grafting (Gie et al 1993) since the graft had been used to fill two large cortical defects, but the technique was the same.

\section{CASE HISTORY}

In 1979 a 64-year-old man had a matt-surfaced Exeter total hip replacement with complete relief of symptoms.

R. S. M. Ling, $O B E$, MA, FRCS Ed(Hon), FRCS, Honorary Consultant Orthopaedic Surgeon

A. J. Timperley, FRCS, Research Fellow

Princess Elizabeth Orthopaedic Hospital, Wonford Road, Exeter, Devon EX2 4UE, UK.

L. Linder, MD, PhD, Consultant Orthopaedic Surgeon

Department of Orthopaedic Surgery, Gävle Hospital, S-801 87 Gävle, Sweden.

Correspondence should be sent to Dr L. Linder.

(C)1993 British Editorial Society of Bone and Joint Surgery $0301-620 X / 93 / 5609 \$ 2.00$
In 1984 an endosteal lytic lesion developed in zone 2 (Gruen, McNeice and Amstutz 1979); this was explored, multiple cultures were taken, and the cortical window was filled with cement. The cultures grew no organisms but histological examination showed a foreign-body granuloma.

Two years later, after a symptom-free period, pain recurred and radiography showed a fracture of the femoral stem at the level of the earlier bone lesion (Fig. 1). At the second reoperation infection could not be excluded; the cup, stem and cement were removed to leave a Girdlestone pseudarthrosis. The distal cement in the femur was removed through a window in the lateral cortex (Fig. 2).

The cultures were negative for infection, and in 1988 , one year after prosthesis extraction, a further Exeter total hip replacement was performed. The cortical defects seen in Figure 2 were covered with thin wire mesh wired into place. Allograft chips were then introduced into the medullary cavity and impacted with an oversized Exeter stem, care being taken to fill the cortical defects. Low-viscosity cement was sucked down and a polished-surface, heavy-duty Exeter stem of normal length was implanted. After six weeks in bed the patient was mobilised on crutches for another three months and then allowed to take full weight. In July 1990 he was completely painfree and radiography showed healing of the cortical defects (Fig. 3).

The patient died from unrelated causes in July 1991 and his femur was removed and kept in $10 \%$ formalin for several months. Serial transverse, 2 to $5 \mathrm{~mm}$ thick sections were then cut on a bandsaw at the level of the two cortical defects. Slab radiographs were taken, and two sections from the upper grafted area and one from the lower area were processed for histology.

Histology. The wire mesh was carefully removed from the specimens and after completion of the fixation, sections were dehydrated in a graded series of ethanol, defatted in xylol and embedded in methylmethacrylate. The xylol treatment dissolved out the cement. Since we were not able to cut the whole cross-section of the femur, sectors of the circumference were cut out to include the grafted areas and the adjacent cortices. Serial transverse, 3 to $5 \mu \mathrm{m}$ sections of the graft were obtained and stained 


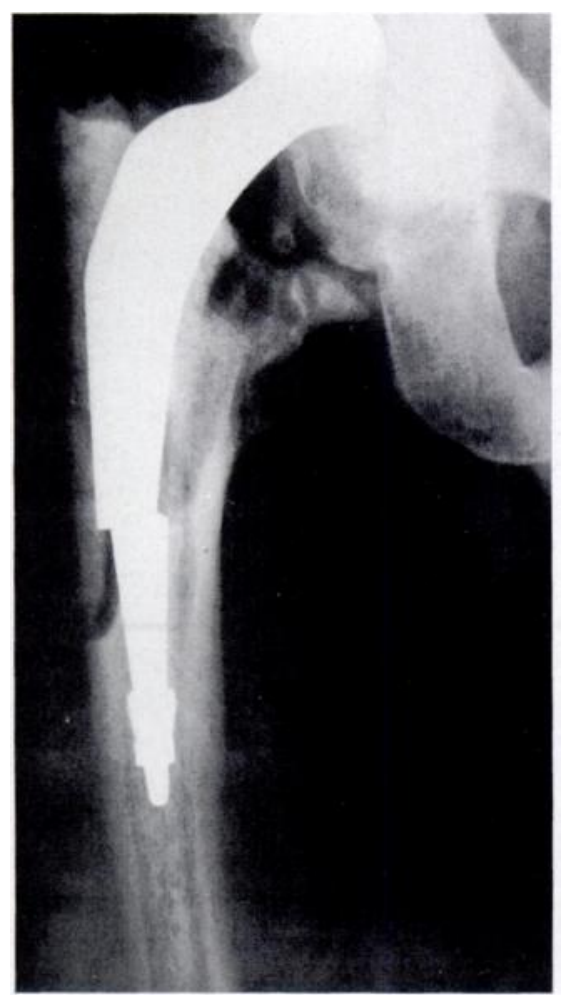

Fig. 1

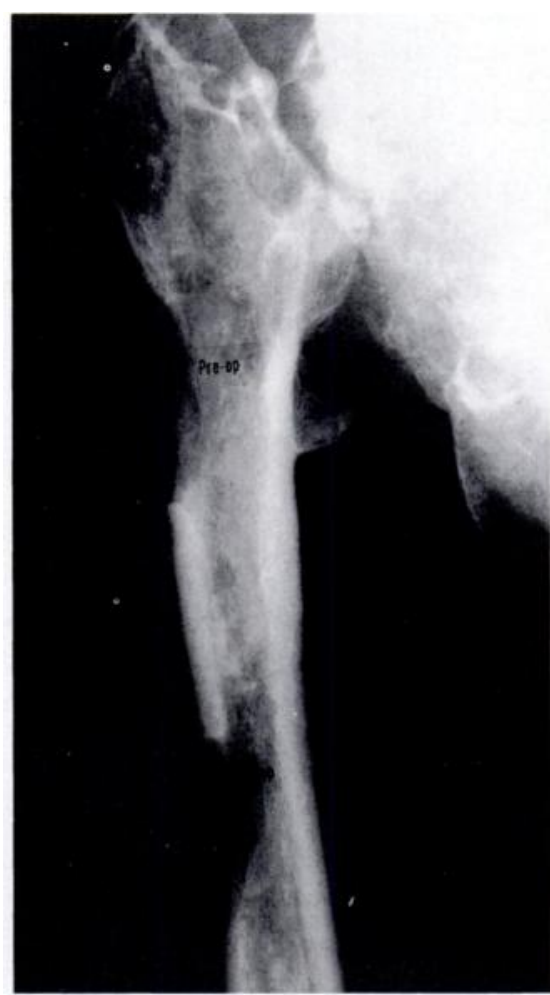

Fig. 2

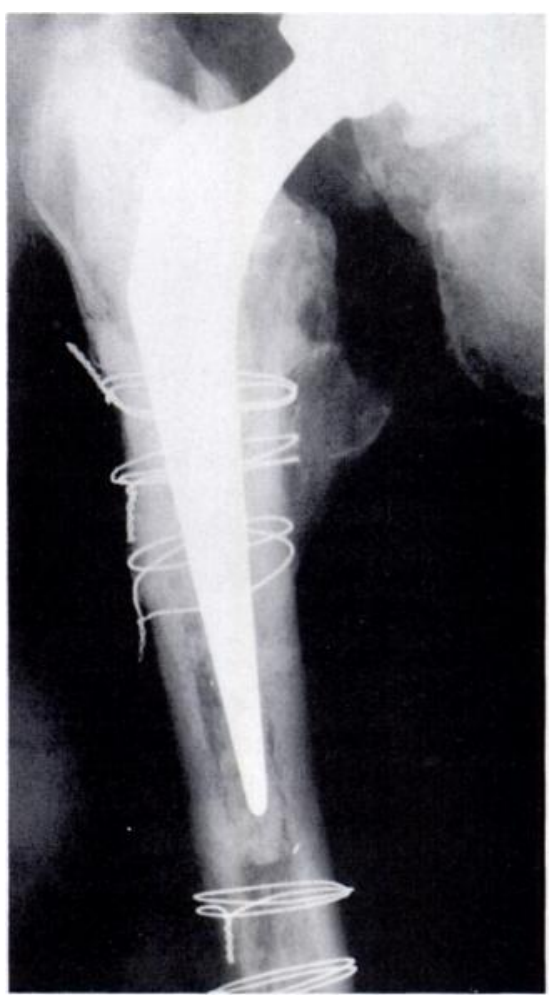

Fig. 3

Figure 1 - The fractured femoral stem with an adjacent cortical defect (see text). Figure 2 - The femur one year after the removal of the prosthesis and cement. There are two cortical defects; the distal one was created surgically to remove the distal cement. Figure 3 - Two years after revision arthroplasty with impaction cancellous grafting. The cerclage wires which secure the wire mesh mark the levels of the cortical defects; these appear to be filled by bone.

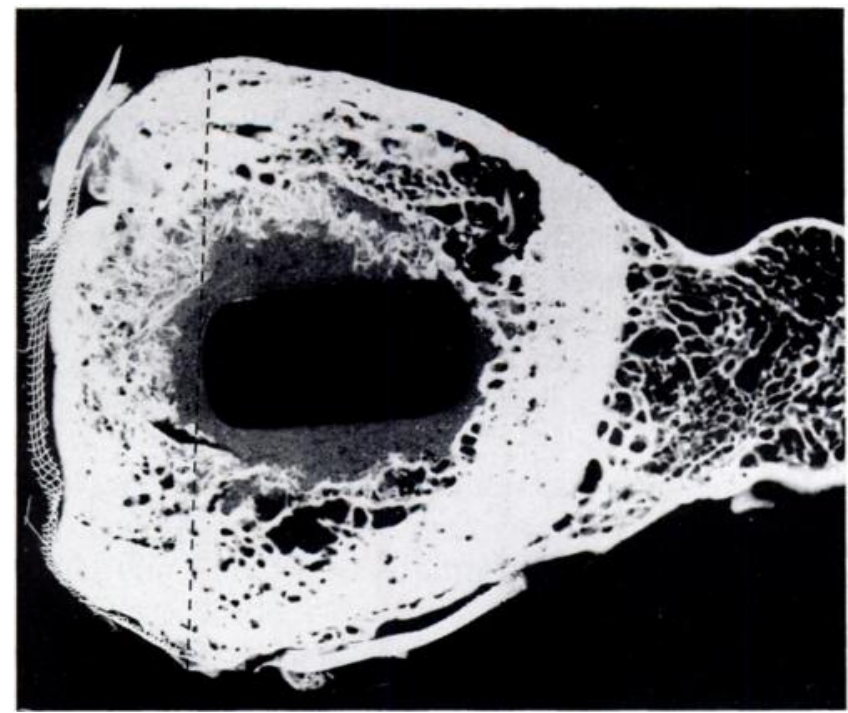

with Richardson's methylene blue, toluidine blue-basic fuchsin, and Goldner stains.

\section{RESULTS}

Radiographs of the bone slabs taken at the centre of the femoral stem showed regeneration of bone with an apparently normal cortical texture under the wire mesh
Fig. 4

Slab radiograph of a transverse section taken at the level of the upper cortical window. The stem has been removed from the cement mantle, and the wire mesh is seen laterally. The grafted area is filled with mineralised bone of normal appearance. The penetration of cement into the bone can be seen. The dashed line indicates the specimen that was taken for histological examination.
(Fig. 4). This newly formed bone had united with the neighbouring cortex except in small areas where cement had protruded between the graft and the original cortex. Cement had also protruded 1 to $2 \mathrm{~mm}$ into the cancellous network of the bone.

Histological findings. The grafted bone had become organised into three zones (Fig. 5). On the surface there was regenerated cortical bone, and beneath this the 


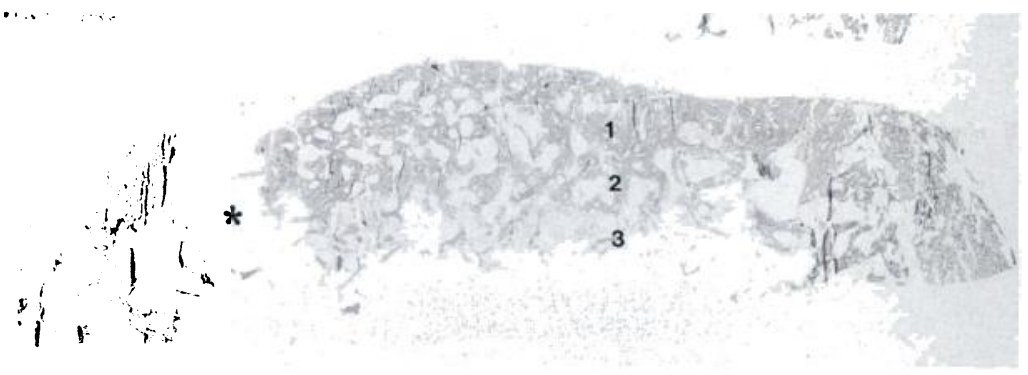

Fig. 5

Low-power view of a histological section taken at the level of the upper cortical window. Cement has been dissolved out and the staining indicates mineralised bone. At one point $\left({ }^{*}\right)$, cement has protruded between the cortex and the graft. The three zones of interest are shown: 1, cortical bone; 2 , interface between living tissue and cement; and 3 , bone trabeculae buried in the cement (Goldner stain $\times 4$ ).

interface between cement and living tissue. The deepest layer was of bone trabeculae entombed in the cement.

Regenerated cortical bone. The bone corresponding to the radiographic cortical bone was fully mineralised with normal vascular channels and larger spaces containing normal-looking fatty bone marrow. The marrow showed no fibrosis and only scattered, small areas of round-cell infiltration in some spaces. The bone was generally viable, as shown by filled osteocyte lacunae (Fig. 6), but there were occasional islands of dead bone. Over $90 \%$ of the total surface area of the sections of new cortical bone contained filled osteocyte lacunae.

Interface zone. This was irregular with direct contact between the bone cement and osteoid. Foreign-body giant cells were visible and in some areas there was a thin soft-tissue lining (Fig. 7). We found no instance of direct contact between viable mineralised bone and cement.

Deep layer. This layer included trabeculae of dead bone, entombed in cement at the time of its insertion. These trabeculae had empty lacunae, but were linked to the surrounding viable bone by bridges of various types of tissue including soft tissues, osteoid and bone (Fig. 7).

Sections taken from the lower window of the femur, below the cement mantle, showed the regeneration of viable bone with normal marrow spaces, which was indistinguishable from normal cortical bone.

\section{DISCUSSION}

The bone specimens were taken from the levels at which cancellous allografts had been placed, and it was clear that the graft peripheral to the cement mantle had been more or less completely replaced by living bone tissue with a normal cortical texture. The replacement of bone graft by viable bone is not surprising, but it is of interest that a direct contact had been formed between osteoid and bone cement. The appearance of the interface tissue was much the same as that reported for primary arthroplasties, with areas of direct osteoid-cement contact alternating with stretches of foreign-body giant cells (Charnley 1979; Lintner, Bösch and Brand 1982)

Our hypothesis is that the bone cement forced into the graft immobilises the bone trabeculae at the interface: the composite behaves more like a bone-coated implant than a solid implant inserted into bone. The healing sequence is unknown, but it seems clear that regenerating

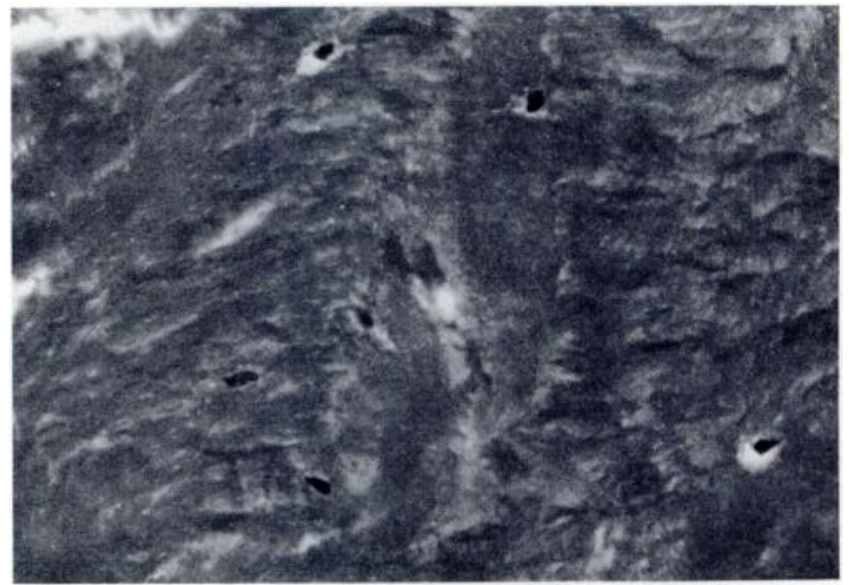

Fig. 6

High-power view of regenerated bone showing filled osteocyte lacunae in a mineralised stroma with all the histological characteristics of normal cortical bone (Goldner stain $\times 600$ ).

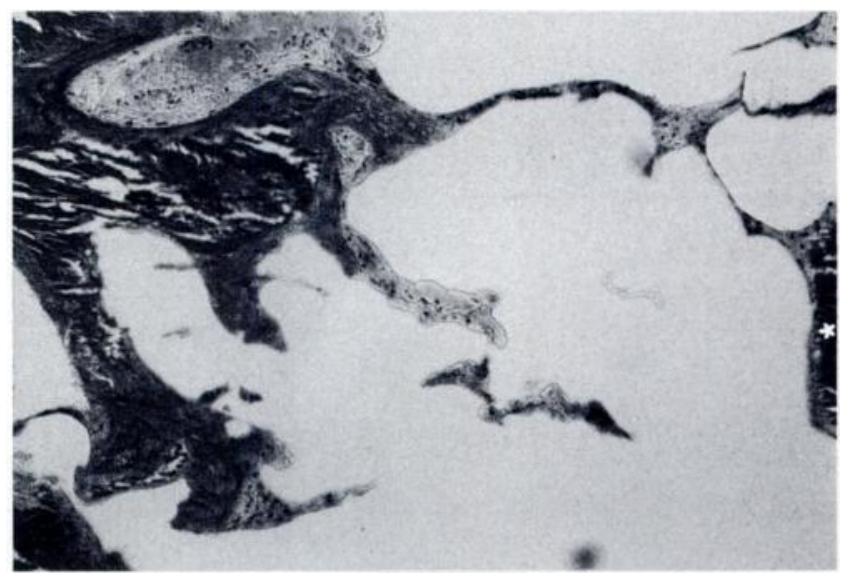

Fig. 7

The interface between viable tissue and the bone cement which has been dissolved out. Viable bone is capped with osteoid which is in direct contact with the (absent) cement surface. Some dead bone trabeculae $\left(^{*}\right)$ are probably remnants of the graft. There are bridges of soft tissue and osteoid which connect these trabeculae to living bone. Multinucleated giant cells are also seen in contact with the cement surface (Goldner stain $\times 120$ ).

bone and osteoid make contact both with the cement surface and with the protruding, dead allograft trabeculae and create a very large load-bearing area. It is uncertain how much of the entombed trabeculae will become resorbed and replaced by other types of tissue, but there 
were histological signs that viable tissue may grow into at least the superficial interstices of the cement.

The clinical follow-up of this patient was only three years, but the biological changes can be regarded as longterm since the regeneration of the cortical bone was more or less complete, and the histology of the interface was similar to that seen around primary cemented arthroplasties. This distinction is important because the radiographs of most patients after impaction cancellous grafting clearly show the same appearance of gradual normalisation of bone structure adjacent to the bone cement (Gie

\section{REFERENCES}

Charnley J. Cement-bone interface. In: Charnley, J, ed. Low friction arthroplasty of the hip: theory and practice. Berlin, etc: SpringerVerlag, $1979 ; 25-40$.

Gie G, Linder L, Ling RSM, et al. Impaction cancellous allografts and cement for revision total hip arthroplasty. J Bone Joint Surg [Br] 1993; 75-B:14-21. et al 1993). The histological findings in this case therefore add further support to the continued use of impaction cancellous grafting in the femur.

The authors are indebted to Mrs Lisbeth Lindberg, Department of Orthopaedic Surgery, Malmö General Hospital, Sweden, who prepared the histological sections.

One or more of the authors have received or will receive benefits for personal or professional use from a commercial party related directly or indirectly to the subject of this article. In addition benefits have also been or will be directed to a research fund, foundation, educational institution, or other non-profit institution with which one or more of the authors is associated.

Gruen TA, McNeice GM, Amstutz HC. "Modes of failure" of cemented stem-type femoral components. Clin Orthop 1979; 141 :17-27.

Lintner F, Bösch P, Brand G. Histologische Untersuchungen über Umbauvorgänge an der Zement-Knochengrenze bei Endoprothesen nach 3- bis 10-jähriger Implantation. Pathol Res Pract 1982; 173:376-89. 